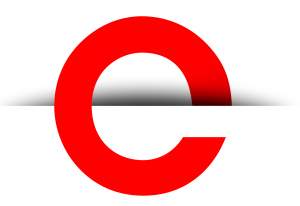

U T S

e PRES S
Gateways:

International Journal

of Community

Research and

Engagement

Vol. 14, No. 2

December 2021

(c) 2021 by the author(s). This is an Open Access article distributed under the terms of the Creative Commons Attribution 4.0 International (CC BY 4.0) License (https:// creativecommons.org/licenses/ by/4.0/), allowing third parties to copy and redistribute the material in any medium or format and to remix, transform, and build upon the material for any purpose, even commercial, provided the original work is properly cited and states its license.

Citation: Ross, L., Byrne, K., and Safford, J. 2021.

Navigating the Boundaries of Youth Violence Prevention and Reduction: Reflections on Power in Community Engaged Scholarship. Gateways: International Journal of Community Research and Engagement, 14:2, 1-12. http://dx.doi.org/10.5130/ijcre. v14i2.7756

ISSN 1836-3393 | Published by UTS ePRESS I http://ijcre. epress.lib.uts.edu.au
RESEARCH ARTICLE (PEER-REVIEWED)

\section{Navigating the Boundaries of Youth Violence Prevention and Reduction: Reflections on Power in Community Engaged Scholarship}

\author{
Laurie Ross ${ }^{1}$, Katie Byrne ${ }^{2}$ and Jennifer Safford ${ }^{3}$ \\ ${ }_{1}^{1}$ Professor of Community Development and Planning, Department of International Development, \\ Community and Environment, Clark University, Worcester, MA USA \\ ${ }^{2}$ Detention Reform Specialist, Commonwealth of Massachusetts, USA \\ ${ }^{3}$ Director of Operations, Collaborative for Youth and Community Justice, Clark University, \\ Worcester, MA, USA
}

DOI: $\underline{\text { http://dx.doi.org/10.5130/ijcre.v14i2.7756 }}$

Article History: Received 09/06/2021; Revised 08/10/2021; Accepted 15/10/2021;

Published 12/2021

\begin{abstract}
Community-engaged scholars grapple with power asymmetries in community-university partnerships, generally working from the assumption that deliberate practices are required to moderate the researchers' power vis-a-vis that of the community. In this article, we suggest that this dyadic framing masks the complexity of power dynamics within communities, of which the university is just one part, and examine how power is negotiated in the boundary zones of a partnership. We use Third Generation Cultural Historical Activity Theory (CHAT) as a conceptual framework to analyse the structural and cultural dimensions of the boundary zone in which research, learning and action in our partnership occurred (Engeström 1996). A brief story sheds light on our boundary work which uses research and data to span, broker and shake institutional boundaries for the purpose of youth violence prevention and intervention. Our analysis illuminates the potential and limitations of our power to foster transformational change. It also allows us to show that underestimating power differentials and the diversity of values and cultures within an organisation and between a university and a community partner, and certainly across multiple institutions in the case of a cross-sector partnership, can slow down and even thwart work to address societal problems.
\end{abstract}




\section{Keywords \\ Boundary Work; Boundary Objects; Community-University Partnership; Youth Violence; Research Partner}

\section{Introduction}

Recognising that persistent societal problems require authentic knowledge co-creation (Ramaley 2014; Saltmarsh \& Hartley 2011; Wegemer et al. 2020), community-engaged scholars have been compelled to grapple with power asymmetries in community-university partnerships. Community-engaged scholars generally work from the assumption that deliberate practices are required to moderate researchers' power vis-a-vis that of the community (Stoecker, Hilgendorf \& Tryon 2009; Wallerstein \& Duran 2017). Our experience working in a long-term (8+ years) cross-sector initiative to reduce youth and gang violence suggests that this dyadic framing masks the complexity of power dynamics within communities of which the university is just one part. Even models that attempt to differentiate positions, roles and actors within communities and universities tend to amplify the complexity of the university over that of the community (Bringle, Clayton \& Price 2009; Sandmann et al. 2014). Underestimating power differentials and the diversity of values and cultures within an organisation, between a university and a community partner, and certainly across multiple institutions in the case of a cross-sector partnership, can slow down and even thwart work to address societal problems.

Rather than examining the dyadic or cross-sector partnership as the unit of analysis, a group of scholars across multiple disciplines are finding it generative to examine how power is negotiated in the boundary zones of a partnership (Akkerman \& Bakker 2011; McMillan, Goodman \& Schmid 2016; Penuel et al. 2015; Romero 2014). More specifically, Third Generation Cultural Historical Activity Theory (CHAT) offers a conceptual framework to analyse the structural and cultural dimensions of the boundary zone in which research, learning and action occur (Engeström 1996).

Before delving deeper into a discussion of boundary zones and CHAT, we tell a brief story that highlights the nature of the boundaries we navigated as the research partner in the Youth Violence Prevention Initiative (YVPI), a city's cross-sector organisational change response to youth and young adult violence. Located in a mid-sized city in the northeast region of the United States, the YVPI is an uneven collaboration of local and state government, law enforcement, public schools, non-profit organisations, youth and families affected by violence, and ourselves as the research partner. We use the term uneven to acknowledge that our ability to involve youth and families as collaborators has been a challenge over the years. Part of the reason authentic community involvement has been challenging is due to the design of the YVPI. Siloed efforts and lack of communication and information sharing across public and non-profit sectors had been identified as factors that made it difficult to reduce violence in the city. We needed the sector and organisational leaders at the table so they could use their positional power to make needed policy and systems change. Yet, the decision to structure the Initiative around the decision-makers proved to make community involvement challenging (Wolff et al. 2017).

In March 2018, the city manager and his chief of operations invited us (the research team) to a meeting that had been requested by the Chief of Police to discuss the YVPI. As the research partner providing the research and data to undergird the YVPI's plan, we became the point of contact for concerns related to the plan as we were viewed as having the power of the pen through the reports we generated. The Chief attended the meeting, accompanied by the police captain most involved with the YVPI. In this meeting, we learned that the police were concerned by our use of the term structural racism in the Initiative's materials because they did not believe structural racism was a factor in youth violence in the city. They felt so strongly about this that they said they could no longer participate in the Initiative if we continued to use the term structural racism. 
We were surprised by the police concern, largely due to timing. Since 2016, the following had been the mission of the YVPI:

The Youth Violence Prevention Initiative was founded on the mission to reduce youth violence in the city by eliminating structural racism and promoting trust, safety, healing, and opportunities for our most under-resourced youth and families. This will be achieved through policy and system change that ensures equitable distribution of resources and opportunities, collaboration that breaks institutional and organisational siloes, and transparency of process and outcomes through consistent information sharing.

This statement had been read out loud at the first Governance Council meeting in 2017, at which the police had been present. The Initiative's Planning Team, a group comprising a liaison of each sector leader and ourselves that meets weekly, crafted the mission statement. We had anticipated that there might be pushback on the use of the term, but no one at the Governance Council meeting even commented on it. From that day forward, we intentionally included the mission in every monthly data report we produced to keep the focus on the purpose of the YVPI.

As we reflected on what could have caused their concern a year and half after we had highlighted structural racism as a causal factor of violence in the city, we thought about the work we had started in fall 2017 for an updated community assessment of the drivers of violence. As part of that preparation, we developed an analysis of arrest and gun/knife incident data from 2015 (our baseline year) through 2017. We found that youth arrests had declined 12.5 per cent and gun/knife incidents had declined almost 20 per cent. Yet, when we disaggregated the data by race and ethnicity, we found that inequities markedly increased between White youth and youth of colour. Rates of White youth arrests and involvement in gun and knife incidents were decreasing faster than those for Black and Latinx youth even though White youth were not the primary target population for most of the YVPI's strategies. We therefore began to include a Relative Rate Index analysis of youth arrests in the monthly data reports to highlight the growing inequity. A Relative Rate Index (RRI) facilitates comparison of different groups of youth within the juvenile justice system. When groups (e.g. Black youth and White youth) are treated equally, both will have an RRI of 1 , regardless of differences in sizes of the groups. RRIs greater or less than 1 indicate an inequity in treatment and outcomes. At our next Governance Council meeting (January 2018), we presented the year end 2017 report, including the RRI, which clearly showed the growing inequity. Police representatives did start to ask whether arrests were an appropriate indicator of youth violence. We sensed that, by asking this question about the use of arrests as an indicator, the police were feeling like we were challenging their work and actions rather than focusing on the Initiative's overall effort to reduce violence.

And so this brings us to the March 2018 meeting with the City Manager and Chief of Police and their staff. In spite of our surprise regarding their concern and that we were deeply conflicted about not calling out structural racism, we recognised the police as being a key partner in any efforts to reduce youth violence. And so we worked with them to develop alternative language. In the end, it was a small adjustment. We replaced 'structural racism' with the term 'structural violence'. When defining structural violence, we used Keith Morton's (2019) definition:

Evidence of structural violence is found by studying patterns of social suffering and asking what produces them: why is poverty so consistently correlated with one or more social identities such as race? Why is domestic violence enacted disproportionately by men against women? Why does enforcement of drug laws result in mass incarceration of people of color? Structural violence happens when we do not recognize how one thing is connected to another, or when we determine that elements of systems are not connected or can be treated differently. Structural violence becomes visible as we practice an ecological way of seeing relationship. 
U T S

e PRES S
We find it interesting that this definition sat more easily with the police even though it directly implicates institutions in perpetuating inequity. It suggests to us the extent of fragility around the term racism. In addition to this operating definition of structural violence, we included an explanation for why we used measures of arrests, school discipline and court-based outcomes to monitor the YVPI's progress. From that point forward, in the written explanation that accompanied our monthly data reports, we emphasised that we were not inherently interested in arrests or suspensions, but that they were the only available data that could serve as indicators of systemic change in the community. With these modifications, the police agreed to continue participating and sharing their data.

This brief story provides a glimpse into what was a much more complex dynamic, fraught with tension and many discussions and emails with other members of the YVPI. We worried that, while we only made a small change to the language, this change could signal to other partners and community members affected by violence a retreat from working on structural racism as a causal factor. The story also provides an opening to examine the nuanced ways power operates in cross-sector initiatives that involve university partners.

\section{Theorising the Boundary Zone through CHAT}

Cultural-historical theories see diversity and difference as inherently valuable to social and professional activity rather than as obstacles to be overcome (Penuel et al. 2015). CHAT posits that, in the context of relationships in communities of practice, learning and action are developed through dialogue and reflection (Foot 2014). Due to its emphasis that learning and action is contextual and that it emerges from communities, CHAT is a useful framework for visualising how power is negotiated within the boundary zones of a partnership. Activity systems are the building blocks of boundary zones. Activity systems consist of six components that interact to produce knowledge and action. These six components are illustrated in Figure 1 (adapted from McMillan, Goodman \& Schmid 2016):

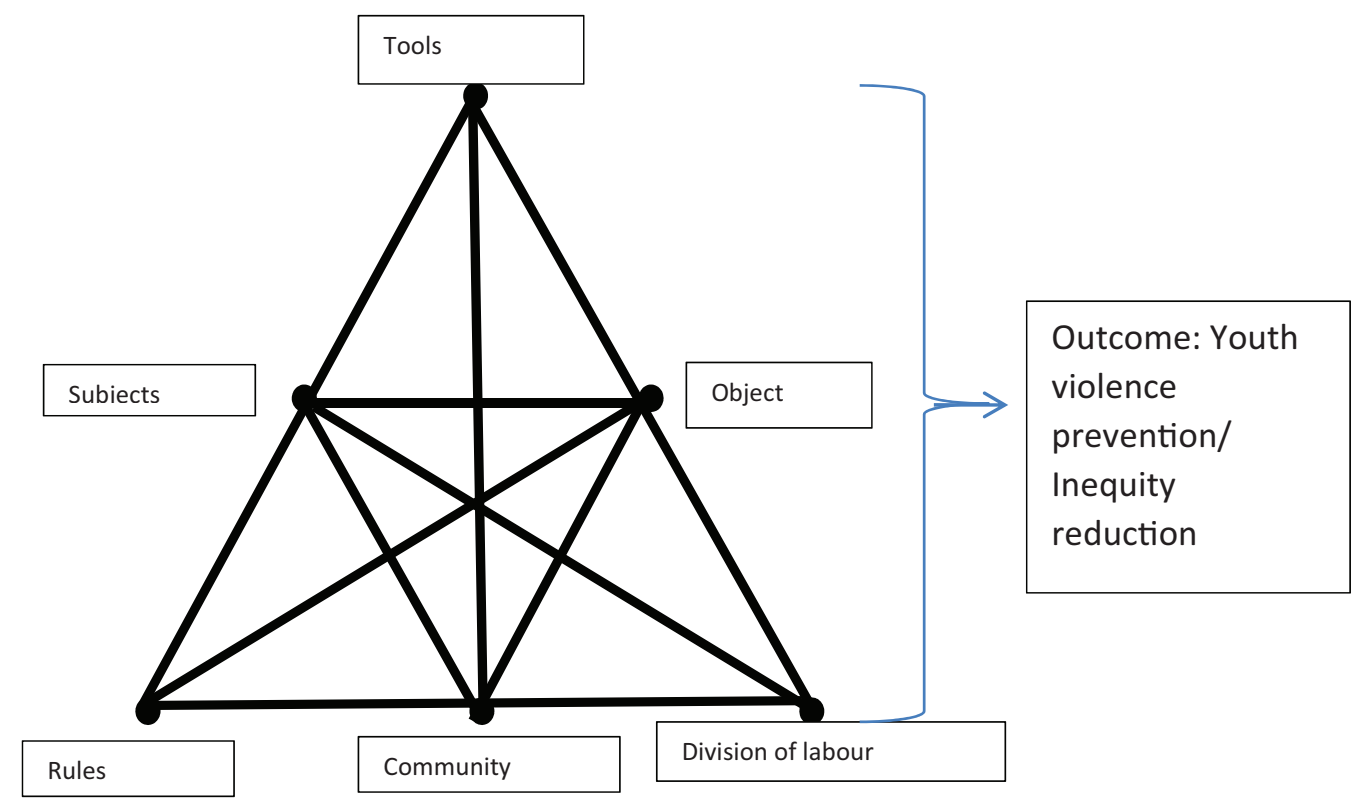

Figure 1. Single activity system

We illustrate these six components within the activity system of our research team. The subjects, the individuals involved in the activity, are the authors of this article. One of us is a tenured professor, one works as a project manager on our youth violence grants and is an adjunct professor, and one of us is a former 
U T S

e P RES S

student and research assistant on the YVPI. The community is the broader group interacting in the activity, of which the subjects are a part - in our case the larger community is our university. The rules encompass both formal and informal agreements, norms, habits, conventions and routines that govern the behaviour of the subjects - in our case Institutional Review Board (IRB) policies that guide research with human subjects, Memoranda of Understanding (MOUs) that spell out terms of partnerships, including data sharing agreements, represent the formal rules that shape the conditions of our engagement. The division of labour refers to the different roles played by actors in the system - in our case, our group consists of the principal investigator, the project manager and a former graduate research assistant. The object is the reason for the activity system; in our case, it is to develop the youth violence assessment and monthly data reports for the YVPI. These objects are the visible manifestation of the work of our research team's activity system and are what are brought into the boundary zone of the partnership. The tools are what the subjects use to generate action on the object; in our case, tools include research team meetings and collaborative documents. The outcome we are striving for through our activity system is a reduction in youth violence and a reduction in inequitable patterns of punishment that disproportionately and negatively affect Black and Latinx youth.

In this activity system description, we tried to isolate the research team in order to understand the opportunities and limitations of its contribution to the YVPI; however, in Third Generation CHAT, two activity systems are the minimal unit of analysis (Akkerman \& Bakker 2011; McMillan, Goodman \& Schmid 2016). Our objects - the youth violence assessment and other data-based tools that guide decisionmaking about programming and resource allocation - are negotiated, interpreted and used by the other activity systems that make up the YVPI. By using Third Generation CHAT to examine the boundary zone created by the 12+ partner organisations' activity systems that come together in the governance council of the YVPI (which itself is just a subset of all of the actors involved in the YVPI), we begin to make visible the origins of tensions and contradictions in our cross-sector partnership's willingness to identify structural racism as a causal factor for youth violence (see Figure 2: Multiple Activity Systems form a Boundary Zone, which is a partial picture of the partners involved). The size of the individual activity systems is meant to illustrate the unevenness of the partnership based on differences in power and influence the various actors exercised in the particular case discussed in this article. In order to understand the work it takes to introduce and deliberate over objects in the partnership boundary zone, we must delve deeper into boundary concepts.

\section{Boundary Zones, Boundary Work and Boundary Objects}

Following Akkerman and Bakker (2011), we understand boundaries as not only representing the extent of an organisation's work, but also the sociocultural differences between organisations that give rise to discontinuities in interaction and action when attempting to do joint work on something as complex as youth violence. The boundary zone can be understood as a transactional space where there is a coming together of individual areas of practice or individual activity systems with the intention of creating a shared area of practice or a joint activity system (McMillan, Goodman \& Schmidt 2016). Even with shared intention, attempting to bring together differently situated activity systems means that boundary zones can be 'places of challenge, contestation, and playing out of power relations' (McMillan, Goodman \& Schmidt 2016, p. 23). There is a fluidity to these spaces due to the reshuffling that occurs through the development of shared language or common measurement systems (Oldenhof, Putters \& Stoopendaal 2016). Boundary work, therefore, requires negotiating between multiple roles at the interstices of different organisational groups (Azambuja \& Islam 2019; Oldenhof et al. 2016). Due to the challenges navigating what is often a chaotic web of competing and complementary aims, strategies and tactics, the change seen through boundary work is likely to be incremental versus revolutionary or swift (Greenwood \& Hinings 1996; Oldenhof, Putters \& Stoopendaal 2016; Stern \& Green 2005). Figure 2 attempts to provide a visualisation 


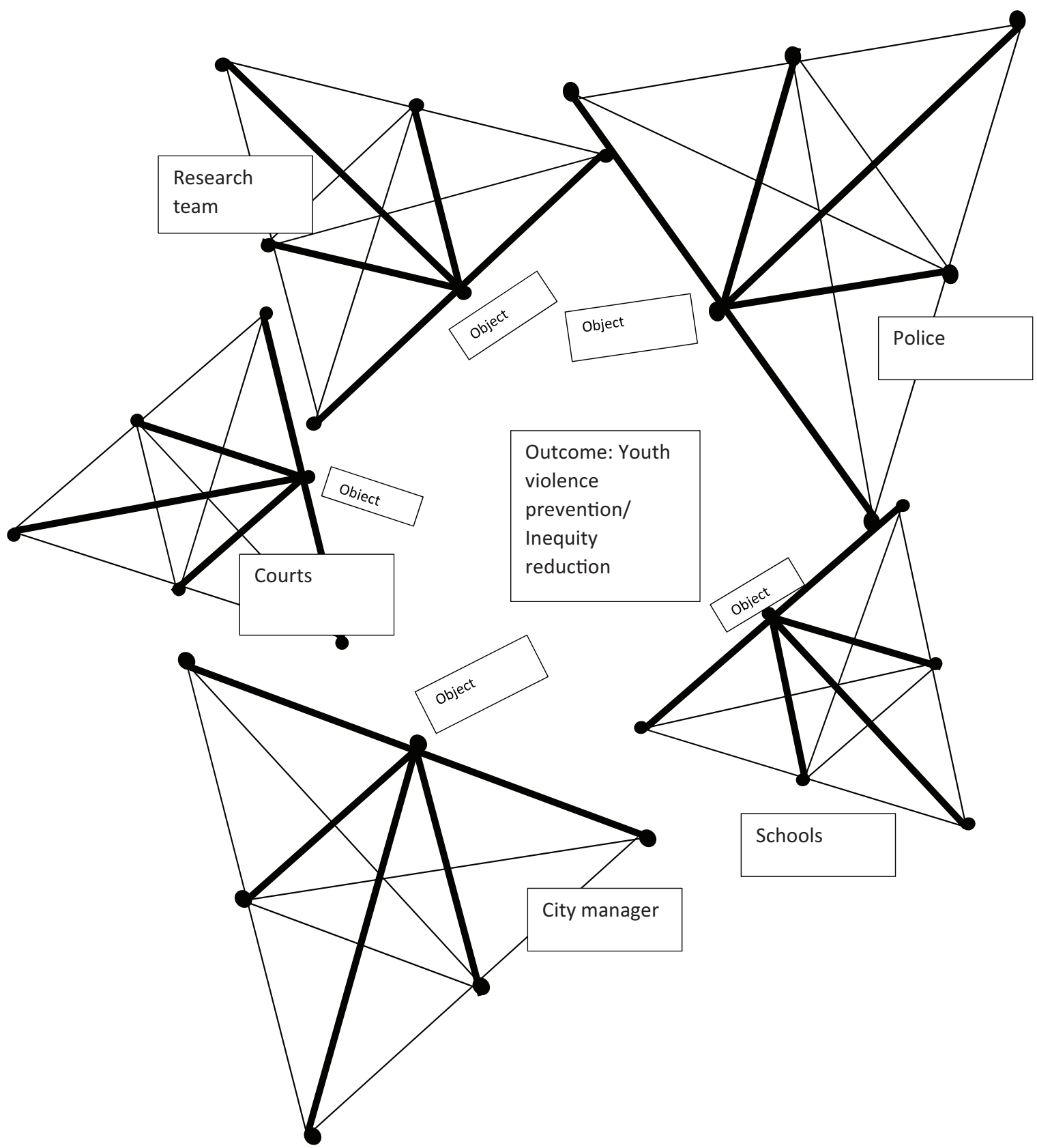

Figure 2. Multiple activity systems form a boundary zone

of this chaotic and uneven web of interests coming together and how the boundary object of any one partner may be visible and recognised, but also contested and misunderstood.

Boundary workers need to be seen as credible within and between organisations to be effective in communicating the intention of boundary objects (Steadman 1992). Trust is crucial in generating momentum for the cross-sector partnership when different activity systems' boundary workers interact (van Meerkerk et al.2017). The successful management of diversity of interests and perspectives requires focus on overcoming discontinuities in actions or interactions, not overcoming or avoiding the difference itself (Akkerman \& Bakker 2011). Boundary work, therefore, does not mean trying to homogenise partners or force unity, but rather learning how to work together to co-generate change in a context of sociocultural difference: different world views, histories, sources of knowledge and practices (McMillan 2011). 
U T S

e PRESS
Given this context, effective boundary workers are savvy and understand the informal and formal norms

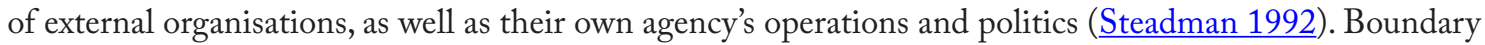
workers take on different roles and are referred to by different names within the literature depending in part on their primary function. Boundary-spanners manage the interface between organisations and their environments, link systems with at least partially conflicting goals or expectations, and facilitate information sharing between people or groups separated by some physical, cognitive, or cultural organisational barrier (Johlke \& Duhan 2001; Oldenhof et al. 2016; Rugkasa, Shortt \& Boydell 2007; Steadman 1992; van Meerkerk \& Edelenbos 2014; van Meerkerk, Zwanenburg \& van Eerd 2017; Williams 2002). Boundary brokers attempt to resolve conflict and increase collaborative spaces (Long, Cunningham \& Braithwaite 2013). Boundary shakers influence existing organisational networks, gather and use knowledge of the organisational political context and motivations of others to pursue transformative change (Balogun et al. $\underline{2005}$.

Boundary workers are not necessarily trying to cross over into other activity systems, but rather are navigating, facilitating and managing at the boundaries of the intersecting systems to achieve a shared objective. To do this, boundary workers use boundary objects to assist with spanning, brokering and shaking of boundaries (Penuel et al. 2015). Boundary objects are intended to satisfy the informational needs of the partners. As shown in Figure 2, the object's meaning emerges and is contested at the nexus of the multiple perspectives, increasing the importance for partners to have some level of understanding of the activity

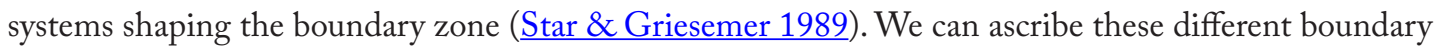
roles to our work, as the research partner, through how we use the boundary object of data, which we consider to be our currency within the Initiative. Our negotiated and facilitated use of data as a boundary object contributes to a level of continuity in the context of socio-cultural difference within the boundary; however, as the story above shows, we did not achieve unity or consensus. We share examples of how our use of data performed different boundary roles and, in so doing, illuminate limitations to our power to foster transformational change.

\section{Case Study: Data as a Boundary Object}

With our conceptual framework laid out, we go back to the story of the meeting with the city manager and the chief and what led up to that meeting. We explore how data and findings derived from them are the boundary objects we bring into the boundary zone of the YVPI.

Early in the development of the YVPI, we occupied a boundary spanning role. One of the first tools that we felt was important to develop to aid communication within the Initiative was a monthly data report. To develop the template for this report, we met individually with the superintendent of schools, the Department of Youth Services, the County's District Attorney and the chief of police to explore with them the data they could share that would be most relevant to the aims of the YVPI. We were then able to develop a data report that presented changes in these indicators to the governance council on a monthly basis. It is important to note that the city manager's liaison accompanied us at these meetings, his presence facilitating the sector leaders' willingness to share data.

The resulting data report can be thought of as a boundary object produced by the research team's activity system. By joining data from these four sectors into one report, we were able to begin to facilitate information sharing among groups with at least partially conflicting goals or expectations. The mission of the YVPI was written on the data report, but in the first year of sharing the reports, we did not explicitly link trends in the data to a structural racism explanation. What we did was provide a structure and a framework within which the partners could operate and process progress on the YVPI. We also hoped the report would help hold people accountable to the work of the Initiative. 
As we started preparing the 2018 community assessment, using Relative Rate Index analysis, a clear picture of increasing inequity emerged. Arrest rates for females and white youth were decreasing at a faster rate than for males and youth of colour even though females and white youth were not the intended primary beneficiaries of the YVPI interventions. As the research team, we recognised that there could be multiple explanations for this trend. We considered that the Initiative may be implementing the wrong interventions or that the interventions were not being implemented with fidelity - meaning that there were insufficient levels of support, insufficient numbers of youth involved, or that programs were not serving young people with sufficient levels of risk. We were cognisant that these types of explanations came from a deficit mindset and could be seen as focusing fault on the implementing organisations or the youth themselves. Wanting to highlight ways systems and structures may be undermining programmatic responses, we began to frame the discussion in terms of inequity in the context of structural racism. In taking this stance and focusing on systemic and structural causes, such as racism, instead of individual behaviour, we understood our boundary work at this time was as boundary shakers. We were using the boundary object of our monthly data reports and presentations to the governance council to pursue transformative change, by problematising the issue outside of the individual and even the agencies providing services, and onto community systems and structures.

Up until the 2018 Governance Council Meeting, it could be argued that, while we had consistently been sharing information that showed disparities, our boundary work had been characterised as spanning. The monthly data report, as the boundary object, was meant to communicate across difference and bring partners together for the shared purpose of youth violence prevention and reduction, and create dialogue at the boundary of socio-cultural difference. When we attempted boundary shaking by framing the boundary object in terms of structural racism, our interpretation was contested by the police who were prepared to leave the YVPI and stop sharing their data. At this point, the city manager operated as a boundary broker, attempting to resolve conflict and maintain the collaborative space. We followed suit in a brokering role and agreed to change the language on the report and provide a rationale for why we use the indicators we do to monitor YVPI progress.

It can be argued that the YVPI has been successful in generating needed programs and initiatives. Developed at least in part due to community needs identified through our research, examples include an intervention program for early childhood trauma, a crisis response team to provide a non-policing response to shooting and stabbing incidents, and a juvenile court diversion program. There is evidence that, when we have been able to achieve a shared understanding of what the data are saying, we have been able to shape and influence community change. Yet, we have been struck by the brokering work we have had to do in providing alternative interpretations of our boundary objects to keep some of the leaders at the table and remain part of the process.

Sector leaders are needed because they can create and change policy, and they now feel like they are on the same page and have become more comfortable about making change collaboratively. Yet, we are aware that this is a group of people who already had power and then we put them in a position to have more power over the process. We had hoped that the boundary objects we produced would help them use their power to apply an equity lens to their policy work. Yet, we are coming to an uneasy recognition that the power dynamic within the boundary zone can reinforce the status quo. Through our attempt at boundary shaking, we learned that we could jeopardise our access to the data we need to perform our role - a role that has contributed to new community interventions. This realisation constrained us in terms of the risks we were willing to take. We have also come to realise that brokering work can act as a process of exclusion of community involvement. The boundary work to keep the leaders at the table had begun to formalise the YVPI as its own activity system - one that had been unable to acknowledge the role of structural racism in youth violence and, in doing so, denied the reality of communities affected by violence. 
This happened in 2018, leaving us to wonder what if it was happening now? Would we still make the same decision to adjust the language used in the mission statement? The nationwide community uprising that occurred after George Floyd was murdered was a powerful and demonstrative account of the strength of a community mobilisation effort aimed at calling out injustice and racism and setting demands for systemic change. In fact, in February of 2021, the city manager signed an executive order acknowledging the role structural and institutional racism has played, and continues to play, in the city. Although it should not take the murder of a black man for city officials to acknowledge the role of racism in systems, structures and institutions, that is what it took for the terms that the YVPI had been using and being challenged on to be incorporated into an executive order, albeit symbolic. Although we cannot change the fact that we decided to step into the boundary brokering role when the police contested the term 'structural racism', we can think about what it could have looked like if we had started the Initiative by bringing community members on board as equal partners with equal power.

\section{Discussion}

During our reflections, we have come to realise the importance of attending to power in the boundary zone of community-university partnerships. The actors within the partnership treated us as a legitimate part of the YVPI. Our legitimacy stemmed partly from the data and research we brought to bear, and how we used the boundary tools to bring systems together. Our partners appreciated that the research and data legitimised the work by allowing us to measure progress through performance indicators. This appreciation diminished, however, when we connected increasing inequity in outcomes with systemic racism. As we demonstrated through the juxtaposition of our Initiative with that of a community uprising, calling out racism does not work if it only occurs internally within an initiative. Perhaps boundary shaking is not enough, and the move to address systemic racism and inequity would be boundary breaking through what

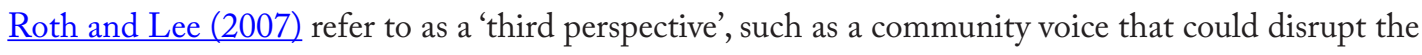
power of the status quo. Understanding the YVPI as a boundary zone illustrates how power plays out in community-university partnerships and the various boundary roles available to research partners. We have come to wonder if our brokering work may have supplanted the power a larger and louder voice from the community could have had, especially if there was shared power within the initiative with the affected community from the beginning (Kegler et al. 2019). Our boundary work established a level of trust within the boundary zone that we were afraid to lose by shaking boundaries, but this trust may have come at the expense of transformative change.

The boundary-spanning role allowed for progress to be made, so we could argue that it was necessary for the health of a collaborative group, but the constraints we faced leave us with questions about alternatives for university-based research partners.

- Given the Initiative's need to bring together and keep sector leaders at the table, what possibilities existed for us to build authentic mechanisms of community involvement in ways that would have avoided the concentrated power of the governance committee?

- What if we had spanned to governance from a boundary zone consisting of community-based organisations? Could our energy have been better spent building community power that could have more deeply influenced formal institutions and policies in ways that would have had more impact on inequity?

- Could we have built data boundary objects in this community-based space to support community activism so that it would have been armed with the legitimacy of research and data sufficient to break boundaries and constitute new forms of power? Would this have allowed a bigger inflection point of change to happen because the motivation would not have been to hold the partnership together, but to let the struggle between the status quo and transformation play out? 
- Given that the lead research partner was a tenured professor with job security, should she have continued to push the YVPI from within the boundary zone as she would have faced minimal threat to her career and standing in her university?

We are not the first to engage with these types of questions, or to think about an alternative model that centres resident power and leadership from the beginning and makes explicit the need to focus on structural issues and systemic racism. The Collaborating for Equity and Justice Toolkit outlines six principles for collaborative-based work in communities that cover some of the themes we have outlined were missing from the core of the YVPI (Wolff et al.2017).

\section{Conclusion}

By focusing on the boundary zone of our partnership, we were able to explore how power operates in the YVPI and the ways in which our development and introduction of boundary objects reinforced and/or disrupted the status quo, specifically as it related to addressing race-based inequities in youth experiences and outcomes. Our boundary work expanded, shook, but ultimately maintained boundaries between organisations intent on addressing the drivers of youth violence. In the end, by creating space around the needs of the formal leaders and decision-makers, the YVPI created a new boundary that has made it difficult for grassroots and community-based partners to enter the boundary zone.

Boundary work allows us to explore questions about how power operates and in what ways our actions and inaction reinforce the status quo, as well as what possibilities exist(ed) for us to open space for other boundary shakers. Ultimately, these reflections raised questions about the value of a university partner. While research and data - our boundary object - can create legitimacy for an initiative, if the research and data threaten the status quo, those with positional power can thwart boundary transformation. Our hope is that engaging in these dialogues through the lens of boundary work will increase our understanding of the complexities of power in community-engaged scholarship and suggest new approaches for readying researchers and community partners to engage in and use their boundary work to lead to deeper community change.

\section{Citations}

Akkerman, S \& Bakker, A 2011, 'Boundary crossing and boundary objects', Review of Educational Research, vol. 81, no. 2, pp. 132-69. https://doi.org/10.3102/0034654311404435

Azambuja, R \& Islam, G 2019, 'Working at the boundaries: Middle managerial work as a source of emancipation and alienation', Human Relations, vol. 72, no. 3, pp. 534-64. https://doi.org/10.1177/0018726718785669

Balogun, J, Gleadle, P, Hope-Hailey, V \& Willmott, H 2005, 'Managing change across boundaries: Boundary-shaking practices', British Journal of Management, vol. 16, no. 4, pp. 261-78. https://doi.org/10.1111/j.1467-8551.2005.00463.x

Bringle, R, Clayton, P \& Price, M 2009, 'Partnerships in service learning and civic engagement', Partnerships: A Journal of Service-Learning and Civic Engagement, vol. 1, no. 1, pp. 1-20.

Engeström, Y 1996, Perspectives on activity theory, Cambridge University Press, Cambridge.

Foot, K 2014, 'Cultural historical activity theory: Exploring a theory to inform practice and research', Jounral of Human Behavior in the Social Environment, vol. 24, no. 2, pp. 329-347. https://doi.org/10.1080/10911359.2013.831011

Greenwood, R \& Hinings, C 1996, 'Understanding radical organizational change: Bringing together the old and the new institutionalism', The Academy of Management Review, vol. 21, no. 4, pp. 1022-54. https://doi.org/10.2307/259163

Johlke, M \& Duhan, D 2001, 'Supervisor communication practices and boundary spanner role ambiguity', Journal of Managerial Issues, vol. 13, no. 1, pp. 87-101. 
Kegler, M, Wolff, T, Christens, B, Dunn Butterfoss, F, Francisco, V \& Orleans, T 2019, 'Strengthening our collaborative approaches for advancing equity and justice', Health Education and Behavior, vol. 46, no. 1, pp. 5S-8S. https://doi. org/10.1177/1090198119871887

Long, J, Cunningham, F \& Braithwaite, J 2013, 'Bridgers, brokers and boundary spanners in collaborative networks: A systematic review, BMC Health Services Research, vol. 13, no. 158, pp. 1-13. https://doi.org/10.1186/1472-6963-13-158

McMillan, J 2011, 'Boundary workers and their importance to community-university partnerships', Metropolitan Universities, vol. 22, no. 2, pp. 106-120.

McMillan, J, Goodman, S \& Schmid, B 2016, 'Illuminating “transaction spaces” in higher education: Universitycommunity partnerships and brokering as "boundary work", Journal of Higher Education Outreach and Engagement, vol. 20, no. 3, pp. 8-31.

Morton, K 2019, Getting out: Youth gangs, violence, and positive change, University of Massachusetts Press, Amherst MA. https://doi.org/10.2307/j.ctvpbnn66

Oldenhof, L, Putters, K \& Stoopendaal, A 2016, 'From boundaries to boundary work: Middle managers creating inter-organizational change', Journal of Health Organization and Management, vol. 30, no. 8, pp. 1204-20. https://doi. org/10.1108/JHOM-03-2016-0041

Penuel, W, Allen, A, Coburn, C \& Farrell, C 2015, 'Conceptualizing research-practice partnerships as joint work at boundaries', Journal of Education for Students Placed at Risk (JESPAR), vol. 20, iss. 1-2, pp. 182-97. https://doi.org/10.10 $\underline{80 / 10824669.2014 .988334}$

Ramaley, J 2014, 'The changing role of higher education: Learning to deal with wicked problems', Journal of Higher Education Outreach and Engagement, vol. 18, no. 3, pp. 7-22.

Romero, D 2014, 'Riding the bus: Symbol and vehicle for boundary spanning', Journal of Higher Education Outreach and Engagement, vol. 18, no. 3, pp. 41-54.

Roth, W \& Lee, Y 2007, 'Vygotsky's neglected legacy: Cultural-historical activity theory', Review of Educational Research, vol. 77, no. 2, pp. 186-232. https://doi.org/10.3102/0034654306298273

Rugkasa, J, Shortt, N \& Boydell, L 2007, 'The right tool for the task: "boundary spanners" in 'A partnership approach to tackle fuel poverty in rural Northern Ireland', Health and Social Care in the Community, vol. 15, no. 3, pp. 221-30. $\underline{\text { https://doi.org/10.1111/j.1365-2524.2006.00674.x }}$

Saltmarsh, J \& Hartley, M (eds) 2011, To serve a larger purpose: Engagement for democracy and the transformation of higher education, Temple University Press, Philadelphia, PA.

Sandmann, L, Jordan, J, Mull, C \& Valentine, T 2014, 'Measuring boundary-spanning behaviors in community engagement', Journal of Higher Education Outreach and Engagement, vol. 18, no. 3, pp. 83-96.

Star, S \& Griesemer, J 1989, 'Institutional ecology, translations and boundary objects: Amateurs and professionals in Berkeley's Museum of Vertebrate Zoology, 1907-39', Social Studies of Science, vol. 19, no. 3, pp. 387-420. https://doi. org/10.1177/030631289019003001

Steadman, H 1992, 'Boundary spanners: A key component for the effective interactions of the justice and mental health systems', Law and Human Behavior, vol. 16, no. 1, pp. 75-87. https://doi.org/10.1007/BF02351050

Stern, R \& Green, J 2005, 'Boundary workers and the management of frustration: A case study of two healthy city partnerships', Health Promotion International, vol. 20, no. 3, pp. 269-76. https://doi.org/10.1093/heapro/dai011

Stoecker, R, Hilgendorf, A \& Tryon, E (eds) 2009, The unheard voices: Community organizations and service learning, Temple University Press, Philadelphia PA. 
van Meerkerk, I \& Edelenbos, J 2014, 'The effects of boundary spanners on trust and performance of urban governance networks: Findings from survey research on urban development projects in the Netherlands', Policy Sciences, vol. 47, no. 1, pp. 3-24. https://doi.org/10.1007/s11077-013-9181-2

van Meerkerk, I, Zwanenburg, M \& van Eerd, M 2017, 'Enabling and constraining conditions for boundary-spanning in community-led urban regeneration: A conceptual model', in M van Dijk, J Edelenbos \& K van Rooijen (eds), Urban governance in the realm of complexity, Practical Action Publishing, Rugby, UK.

Wallerstein, N \& Duran, B 2017, 'The theoretical, historical and practice roots of CBPR', in Community-based participatory research for health: Advancing social and health equity, pp. 17-29.

Wegemer, C, Tivaringe, T, Hildreth, R, Pacheco, J \& Sifuentes, M 2020, 'The challenges of putting community first: Reflections on a University Center's process', Michigan Journal of Community Service Learning, vol. 26, no. 1, pp. 53-74. https://doi.org/10.3998/mjcsloa.3239521.0026.105

Williams, P 2002, 'The competent boundary spanner', Public Administration, vol. 80, no. 1, pp. 103-24. https://doi. org/10.1111/1467-9299.00296

Wolff, T, Minkler, M, Wolfe, S, Berkowitz, B, Bowen, L, Dunn Butterfoss, F, Christens, B, Francisco, V, Himmelman A \& Lee, K 2017, 'Collaborating for equity and justice': Moving beyond collective impact', Nonprofit Quarterly. https:// nonprofitquarterlyorg/collaborating-equity-justice-moving-beyond-collective-impact/ 